Brit. F. Psychiat. (1978), 132, 104-112

\title{
Correspondence
}

Letters for publication in the Correspondence columns should not ordinarily be more than 500 words and should be addressed to: The Editor, British Journal of Psychiatry, 17 Belgrave Square, London SWIX 8PG

\section{PSYCHIATRY: SCIENCE AND MEANING}

DEAR SIR,

I thank Professor Hill for his interest in my paper but gather that I have not made myself clear. 'It is whether or not psychiatry (as opposed to psychoanalysis) is or should be concerned with "the self", with the individual psychic reality of the patient which is the important and implied question in Dr Bebbington's paper.' I do not put this in question: indeed my concern is exactly with the psychic reality of the patient and how far we can know it.

Professor Hill criticizes my use of the term 'models of the mind': as his exposition itself involves an idiosyncratic model of the mind-a reductionist melange of psychoanalysis, neurophysiological and cybernetic terminology-I cannot take this criticism seriously. His reductionism has dangers, seen most completely in the following: 'In respect of information which is wholly cognitive, we can assume that the recording is carried out by processes involving digital linkages, but in respect of recording information which is affectively laden the process is determined by linkages which are characterized by their meaning alone.' This appears to be a confusion of two untranslatable modes of description.

Professor Hill remains confusing in the matter of interpersonal perception. He does not distinguish between what someone else experiences, what we perceive of that experience and the process of the perception. Hence: 'It is difficult to see how the validity' (of my conclusions) 'could be tested against the actuality of the patient's experience' (my italics). It is difficult to see how anything can be tested against the actuality of someone else's experience. We can only make an inference from our observations of the other's behaviour and a knowledge of the context of his 'personal plight'. That inference will be informed by our experience of our own and other's behaviour, and this must be ordered somehow to enable us to make predictions. Hence my usage 'models', and I do not see another mechanism for our perception of someone else's psychic reality. Terming this 'identification' is merely a semantic distinction from the process by which we know the physical world. The uniqueness of another's mental world is unknowable: understanding relies on common elements which can form the basis of falsifiable generalizations.

We should be aware of the Jasperian distinction between causal explanation and meaning because it behoves us to know the status of statements we make about patients. If we do not, we run the danger of being merely slanderous. If, however, we use the distinction, as he did, to justify the separation of part of psychiatric language from its scientific base we do psychiatry a disservice. The sooner this is recognized, the better: it is time that 'meaning' returned to its derivative status.

In achieving understanding of a patient we respond to the semantic aspects of the concepts we use. The sole requisite of a language in this sense is that it provides the words for description. However, the language of psychiatrists is a technological one where the concepts derive meaning from hypothetical propositions; it has a 'nomological net' (Cronbach and Meehl, 1955) and this is true of the language of psychoanalysis. Part of Hill's effort is to strengthen this net by his reductionist links with other scientific models of description. Rycroft and his followers, however, are happy about the severence from the nomological net caused by the evasion of test by refutation. Psychoanalytic language has a technological archaeology, but the aspirations only of an ordinary language. My real contention is that this is sad, for I suspect the alternative will be the graveyard of irrelevance.

MRC Social Psychiatry Unit,

Paul Bebington

Institute of Psychiatry,

De Crespigny Park,

London $S E_{5} 8 A F$

\section{References}

Bebbington, P. E. (1977) Psychiatry: Science meaning and purpose. British Fournal of Psychiatry, 130, 222-8.

Cronbagh, L. J. \& Meehl, P. E. (1955) Construct validity in psychological tests. Psychological Bulletin, 52, $28 \mathrm{I}-302$.

Hils, D. (1977) Psychiatry: Meaning and purpose. An answer to Dr Bebbington. British Journal of Psychiatry, 131, 2 I 7-19. 